\title{
DINÂMICA POPULACIONAL E TRANSFORMAÇÕES SOCIOESPACIAIS: UMA ANÁLISE A PARTIR DA REGIÃO DO VALE DO TAQUARI/RS
}

\author{
Júlia Elisabete Barden ${ }^{1}$ \\ Fernanda Cristina W. Sindelar ${ }^{2}$ \\ Rosmari Cazarotto ${ }^{3}$ \\ Gustavo R. da Silva ${ }^{4}$
}

\begin{abstract}
Resumo: Este trabalho objetiva analisar a dinâmica populacional e as transformações socioespaciais que ocorreram na região do Vale do Taquari/RS, a partir da mobilidade ruralurbana e intrarregional. Para tal, foram analisados os dados da população, do Valor Bruto Adicionado e feitas análises cartográficas da região. Dentre as principais características verificadas na região, tem-se: a passagem de uma região essencialmente rural para urbana, tanto em relação à distribuição da população quanto às atividades econômicas; um processo de envelhecimento mais acelerado do que o RS; uma diversificação produtiva, mas com o predomínio do setor de serviços na maioria dos municípios; a concentração da população urbana e da geração da riqueza em torno da cidade polo, Lajeado; e o vínculo da região com a região metropolitana de Porto Alegre.
\end{abstract}

Palavras-chave: Transformação socioespacial; Dinâmica populacional; Região; Vale do Taquari

\section{POPULATION DYNAMIC AND SOCIO-SPATIAL TRANSFORMATIONS: AN ANALYSIS FROM THE TAQUARI VALLEY REGION/RS}

Abstract: This work aims to analyze the population dynamics and socio-spatial transformations that occurred in the Vale do Taquari/RS, based on rural-urban and intrarregional mobility. For that, there were analyzed the data of population, of the Gross Added Value, and there were performed the cartographic analysis of the region. Among the main features verified in the region, there are: the passage of an essentially rural area to an urban area, in relation to population distribution as well as to its economic activities; a more accelerated aging process than in the RS state; a productive diversification, with the predominance of the service sector in most of the towns; the urban concentration of the population and wealth generation around the hub town Lajeado; and the link of the region with the Metropolitan Area of the city of Porto Alegre.

Key-Words: Spatial transformation; Population dynamics; Region; Taquari Valley

\footnotetext{
${ }^{1}$ Professora do Programa de Pós-Graduação em Ambiente e Desenvolvimento -PPGAD da Universidade do Vale do Taquari - Univates. E_mail: jbarden@univates.br.

${ }^{2}$ Professora da Universidade do Vale do Taquari - Univates. E_mail: fernanda@univates.br.

${ }^{3}$ Professora da Universidade do Vale do Taquari - Univates. E_mail: rosmari.cazarotto@ univates.br.

${ }^{4}$ Bolsista de Iniciação a Pesquisa pela Fundação de Amparo a Pesquisa do Estado do RS - Fapergs. E_mail: guhrs@hotmail.com.
} 


\section{DINÁMICA POBLACIONAL Y TRANSFORMACIONES SOCIOESPACIALES: UN ANÁLISIS A PARTIR DE LA REGIÓN DEL VALLE DEL TAQUARI/RS}

Resumen: Este trabajo objetiva analizar la dinámica poblacional y las transformaciones socioespaciales que ocurrieron en la región del Valle del Taquari / RS, a partir de la movilidad rural-urbana e intrarregional. Para ello, se analizaron los datos de la población, del Valor Bruto Añadido y se efectuaron análisis cartográficos de la región. Entre las principales características verificadas en la región, se tiene: el paso de una región esencialmente rural a urbana, tanto en relación a la distribución de la población como a las actividades económicas; un proceso de envejecimiento más acelerado que el RS; una diversificación productiva, pero con el predominio del sector de servicios en la mayoría de los municipios; la concentración de la población urbana y la generación de riqueza en torno a la ciudad polo, Lajeado; y el vínculo de la región con la región metropolitana de Porto Alegre.

Palabras clave: Transformación socioespacial; Dinámica poblacional; Región; Valle del Taquari

\section{INTRODUÇÃO}

As transformações socioespaciais podem ser analisadas, mesmo que parcialmente, a partir da sua dinâmica populacional. Esta dinamicidade pode ocorrer tanto como consequência das relações econômicas e sociais que se estabelecem em um determinado espaço, ou ainda, podem ser estimuladas através de movimentos migratórios ou por meio do desenvolvimento de políticas públicas, e ser as causadoras das mudanças.

Além disso, a consolidação da modernização agrícola deu lugar para novas demandas e padrões de consumo alterando o papel de algumas cidades no Brasil, as quais passaram a responder com novos produtos, equipamentos, serviços e profissionais. Trata-se do consumo produtivo que se relaciona com o consumo da ciência, consultorias e crédito (dinheiro). Diante disso, as inovações tecnológicas, as alterações nas relações de produção e de trabalho provocaram grandes transformações no espaço agrário brasileiro (SANTOS e SILVEIRA, 2008, p. 280).

Sob estes aspectos está a região do Vale do Taquari (VT), localizada na porção centrooriental do Rio Grande do Sul (RS), distante, em média, 150 km de Porto Alegre. Em 2010, o VT possuía 327.723 habitantes, aproximadamente 3\% da população do RS (IBGE, 2010), deste total, 73,8\% residiam nas áreas urbanas e 26,2\% nas áreas rurais. No entanto, este cenário nem sempre foi assim, na década de 1970, 74,2\% da população residia em áreas rurais (IBGE, 1970). Além disso, no período de 1970 até 2010, a população total da região 
aumentou em $41,6 \%$, e passou a concentrar $59,4 \%$ de seus habitantes em seis municípios da região (IBGE, 1970; IBGE, 2010).

Em termos municipais, a região apresentava um número relativamente pequeno de municípios emancipados até o ano de 1950, apenas cinco, e ao longo da década mais quatro municípios se emanciparam. Já no início da década de 1960, cinco novos municípios foram constituídos, e após esse período, o número permaneceu estável por aproximadamente 20 anos. No entanto, ao final da década de 1980 e início da década de 1990, devido à permissão legal e seguindo interesses político-econômicos, intensificou-se a criação de novos municípios, sendo que em 2010 a região contava com um total de 36 municípios, dos quais apenas quatro não se classificavam como cidades pequenas ${ }^{5}$, considerando-se como referência critérios de população. Contudo, ao observar as relações estabelecidas entre espaços urbanos e rurais e com cidades no entorno, verificam-se de disparidades entre elas.

Ademais, a tendência do processo de emancipações também ocorreu no RS, porém no VT foi mais dinâmico, pois houve o surgimento de novos e inúmeros núcleos populacionais, que intensificaram os fluxos migratórios rural-urbano e intra-regionais. Neste sentido, este trabalho tem por objetivo analisar a dinâmica populacional e as transformações socioespaciais da região do Vale do Taquari/RS, a partir das mudanças verificadas na dinâmica populacional rural-urbana e intrarregional.

\section{DINÂMICA POPULACIONAL DO VALE DO TAQUARI}

A região do VT possui características semelhantes ao RS quando se trata da distribuição espacial da população, ou seja, é uma região com a população concentrada nas áreas urbanas e em determinados espaços regionais.

Além disso, embora tenha apresentado taxas de crescimento distintas em determinados períodos, ao longo das últimas décadas, ela manteve a sua representatividade na população estadual, porém apresentou fluxos rural-urbano e intra-regionais mais intensos. Estas características foram construídas ao longo da história, impulsionadas, sobretudo, pela dinâmica das atividades econômicas, fortemente alicerçadas no processo de modernização da agricultura e no desenvolvimento de cadeias agroindustriais.

\footnotetext{
${ }^{5}$ No Brasil, “a definição de população urbana tem um caráter político-administrativo ao incluir todas as sedes de municípios e distritos, independentemente do seu tamanho" (CAMARANO e BELTRÃO, 2000, p. 14).
} 
Em relação à taxa de crescimento anual, conforme dados dos censos demográficos, observa-se que o VT manteve taxas médias de crescimento populacional próximas as do estado entre 1970 e 2010, com exceção do ano de 1980, quando a população regional cresceu apenas $0,45 \%$, enquanto no estado o crescimento foi de $1,55 \%$, demonstrando que nesse período houveram fluxos migratórios para outras regiões. E já no período recente, a taxa de crescimento regional é um pouco superior que no Estado. Em 2010, o crescimento regional foi de $0,77 \%$, contra $0,49 \%$ no RS.

Os dados também demonstram uma discrepância em relação ao comparativo entre o crescimento médio da população urbana da região em relação ao RS, visto que o crescimento da região é superior ao observado no estado. Além disso, a partir da década de 1980, intensificou-se o crescimento da população urbana da região em relação a sua população rural, tendência essa que seguiu nas décadas seguintes, o que demonstra que as áreas urbanas atraíram fluxos migratórios intra e inter-regionais em virtude do desempenho econômico de algumas cidades, mesmo que pequenas.

Além disso, a partir dessa década também é possível observar que a taxa de crescimento da população rural passou a ser negativa tanto na região como no estado, o que levou a um esvaziamento do meio rural, e uma intensificação dos processos de urbanização.

A região foi se modificando e as cidades passaram a ter mais força e projeção de acordo com os interesses do desenvolvimento do capitalismo. Os agricultores familiares da região vivenciaram as transformações decorrentes da modernização da produção agrícola. Momento em que a cadeia produtiva de frangos, suínos e leite se fortaleceram e passaram a se agregar aos complexos agroindustriais com seus respectivos sistemas integrados a indústria de alimentos.

Ainda, quando analisados os dados em termos municipais, verifica-se que alguns municípios atraem população em virtude de sua dinâmica econômica, como é o caso dos municípios de Lajeado e Estrela. Estes municípios apresentaram um crescimento superior a média da região nesta mesma década, enquanto que municípios menos dinâmicos, como Nova Bréscia e Roca Sales, apresentaram uma redução média da população de 2,9\% e 1,9\% respectivamente, sendo essa redução observada tanto no meio rural como no meio urbano. Em 2010, os dois que mais atraíram, Estrela e Lajeado, abrigavam 31\% do total da população do VT. Em termos do total da população urbana da região este valor aumentou para $40 \%$ (FEE, 2010). 
Contudo, vale destacar, que ao longo do período analisado, nem todos os municípios conseguiram manter os atrativos, por isso em alguns momentos eles receberam fluxos migratórios, mas em outros momentos, perderam população. Assim, considerando os dados regionais, verifica-se que o crescimento demográfico e a urbanização, processos que no passado foram mais acelerados, perderam força. Percebe-se que há uma tendência a limitar-se ao crescimento natural, fato observado, em média, nos países da região da América Latina e Caribe (ONU, 2012).

Na Figura 01 é possível visualizar as implicações da trajetória da população do VT em relação ao domicílio.

\section{Figura 01 - Evolução das características dos municípios do Vale do Taquari em relação ao predomínio da população de acordo com o domicílio.}
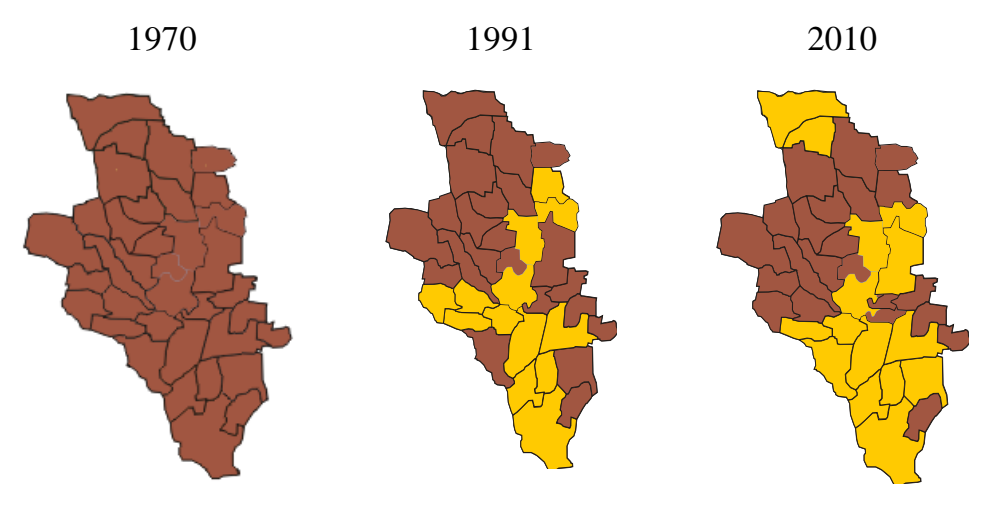

População Rural

População Urbana

Fonte: IBGE (1970 a 2010)

Na década de 1970, todos os municípios eram caracterizados como rurais. Por outro lado, a partir dos anos 1990, e de forma significativa ao final do período, a população urbana passou a concentrar em alguns municípios. Em 2010, observa-se que dos 36 municípios, 21 permaneceram com a maior parte da população residindo no meio rural, embora com população reduzida em relação aos demais que se tornaram essencialmente urbanos e concentradores.

Apesar da região apresentar um percentual superior da população que reside no meio rural, se comparado ao estado, observa-se que ao longo das últimas cinco décadas o processo de urbanização ocorreu de forma mais intensa. Enquanto em 1970, 25,8\% da população regional residiam em áreas urbanas, em 2010 esse percentual passou para 73,8\%. No Estado, no mesmo período, a população residente em áreas urbanas passou de 53,3\% para 85,1\%. Por 
outro lado, percebe-se que a urbanização na região não ocorreu de forma homogênea, com destaque para o município de Lajeado que diverge da média regional, dado que em 2010 apresentava uma taxa de urbanização de $99,62 \%$.

A dinâmica populacional do VT oportunizou uma nova configuração dos espaços, rurais e urbanos. Esse fenômeno pode ser explicado tanto pelo surgimento de novos municípios, o que resultou na delimitação de novas áreas urbanas, como pela substituição das atividades econômicas da região, visto que as atividades primárias deixaram de ser a atividade dominante. Segundo ONU (2012), em geral, cidades menos atrativas do ponto de vista econômico, social e de trabalho perdem sua população para cidades mais dinâmicas e com maior potencial nestes aspectos, constatação esta, que também pode ser feita em relação à região em estudo.

No âmbito de uma região que passou pelo processo de modernização da agricultura, a cidade de Lajeado passou a concentrar a oferta de bens e serviços para uma hinterlândia regional e oferecer uma gama maior de serviços e atividades especializadas destinadas ao mercado nacional e internacional, nos termos de Corrêa (2007) destacando-se a área da saúde, e educação universitária, por exemplo.

Sob este aspecto, novas atividades passaram a ser desenvolvidas na região e vinculadas aos setores industriais e de serviços. Utilizando o Valor Adicionado Bruto (VAB), índice que serve de base para o cálculo do PIB, constata-se que em 1970 o VAB do VT estava distribuído entre os setores econômicos de forma mais equilibrada: o setor agropecuário era responsável por $37,1 \%$ do VAB total; o setor industrial por $26,5 \%$; e o setor de serviços por 36,4\%. Contudo, ao longo das décadas seguintes, a agricultura perdeu participação, enquanto que o setor industrial e o setor de serviços passaram a ser mais importantes. Em 2010, a composição do VAB era substancialmente diferente: o setor agropecuário respondia por $11,9 \%$; o setor industrial por $30,3 \%$; e o setor de serviços passou a representar a principal atividade econômica da região $(57,8 \%)$ (FEE, 2010).

Quando se faz uma análise municipal do VAB, percebe-se que a atividade econômica predominante nos municípios em 2010 segue a mesma tendência da média da região, porém com disparidades significativas. A Figura 02 apresenta o predomínio da atividade econômica nos municípios em 2010. Conforme se observa, os municípios mais populosos são aqueles onde as atividades terciárias ou mistas eram mais desenvolvidas, enquanto que nos municípios com população mais reduzida, predominavam as atividades agrícolas. 


\section{Figura 02 - Municípios do Vale do Taquari conforme o predomínio da atividade econômica em 2010.}

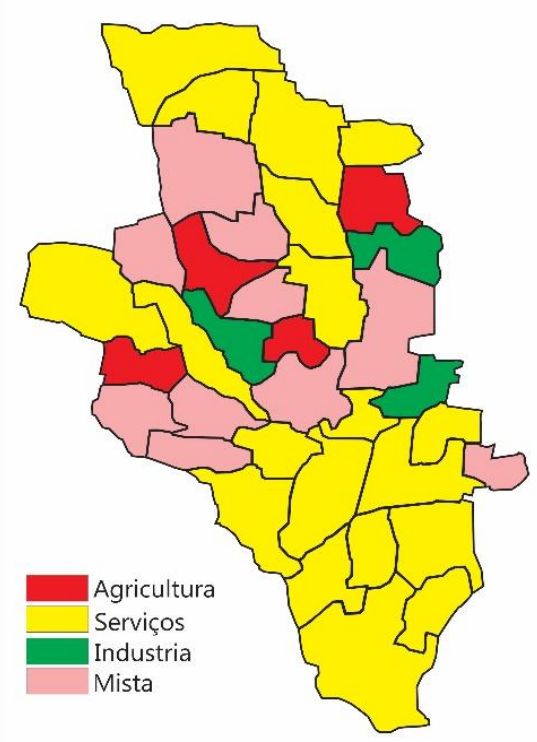

Nota: os municípios foram classificados como de economias mistas quando a diferença percentual na importância na geração do VAB entre dois ou mais setores era inferior a 5\% (APÊNDICE B).

Fonte: Elaborado com base nos dados da FEE (2010).

Em 19 municípios do VT, principalmente pelo fato de concentrar mais habitantes nesses locais, o setor de serviços é o principal gerador da atividade econômica municipal. Em outros 10, observa-se a existência de economias mistas, onde dois setores da atividade se destacam, ou seja, há pelo menos dois setores com participações idênticas na constituição da produção regional, demonstrando um equilíbrio na participação setorial. Ainda, destaca-se que em quatro municípios o principal setor da atividade continua sendo o setor agrícola (Canudos do Vale, Capitão, Coqueiro Baixo e Vespasiano Correa), que responde por mais de $50 \%$ VAB nesses municípios, e somente em três, a atividade industrial é a mais representativa (Imigrante, Muçum e Travesseiro).

A nova espacialidade também pode ser compreendida sob a ótica da densidade demográfica. Verifica-se ao longo das últimas décadas que na região esta foi superior a observada no estado, assim como, o VT também apresentou uma taxa de crescimento superior a do RS. Conforme os dados, a região passou de $19 \mathrm{hab} / \mathrm{km}^{2} \mathrm{em} 1920$ para $67,9 \mathrm{hab} / \mathrm{km}^{2} \mathrm{em}$ 2010. Por outro lado, no RS, inicialmente a densidade demográfica era de aproximadamente de $8 \mathrm{hab} / \mathrm{km}^{2}$ e em 2010 passou para $40 \mathrm{hab} / \mathrm{km}^{2}$. Estas constatações permitem confirmar as observações feitas anteriormente, ou seja, a região recebeu fluxos migratórios de outras 
regiões. Contudo, a região apresentou uma realidade díspar quando se analisa individualmente os municípios. As situações emblemáticas são encontradas em Lajeado e em Coqueiro Baixo: Lajeado apresenta uma densidade demográfica de 792,95 hab $/ \mathrm{km}^{2}$ enquanto em Coqueiro Baixo esta é de 13,61 hab/km² (FIGURA 3)

Figura 03 - Densidade demográfica do Vale do Taquari em $2010\left(\mathrm{hab} / \mathrm{km}^{2}\right)$

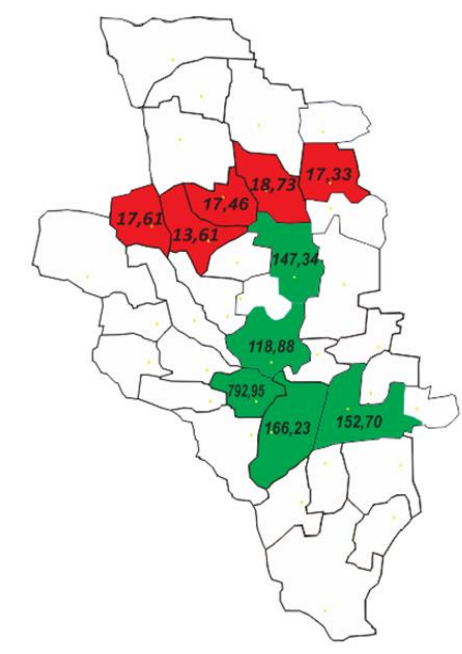

Fonte: IBGE (2010)

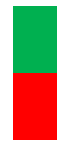

Maiores densidades

Menores densidades

A partir disso, infere-se que a discrepância nas densidades demográficas é consequência do intenso processo de mobilidade que se estabeleceu na região. Além da mobilidade das zonas rurais para as urbanas, houve uma intensa mobilidade dos municípios menores para os maiores.

Os cinco municípios que lideram em relação a densidade demográfica também configuram como os cinco primeiros em relação a geração do PIB da região, e seguem praticamente a mesma hierarquização, exceto uma troca de posições entre Encantado e Arroio do Meio: Lajeado (29,5\%), Estrela (11,9\%), Teutônia (9,7\%), Arroio do Meio (7,2\%) e Encantado (6,1\%) (FEE, 2010). Por outro lado, tendência semelhante ocorre em relação aos municípios com menor densidade, ou seja, estes cinco municípios se encontram entre os que menos contribuem para a formação do PIB do VT (em média, cada um participa com 0,3\% na composição do PIB total da região).

Em relação à estrutura etária da população, verifica-se que ao longo do tempo houve uma redução da participação da população mais jovem até 20 anos, assim como, um 
crescimento da participação da população com 60 anos ou mais tanto no VT como no RS, o que demonstra uma redução da taxa de natalidade e um envelhecimento da população (TABELA 01).

Tabela 01 - Distribuição percentual da população no Vale do Taquari e no Rio Grande do Sul, por faixa etária - 1920 a 2010.

\begin{tabular}{ccccccc}
\hline \multirow{2}{*}{ Anos } & \multicolumn{5}{c}{ DISTRIBUIÇÃO ETÁRIA } \\
\cline { 2 - 7 } & \multicolumn{2}{c}{ De 0 a 20 Anos } & \multicolumn{2}{c}{ De 21 a 59 Anos } & \multicolumn{2}{c}{ De 60 e mais (2) } \\
\cline { 2 - 7 } & $\begin{array}{c}\text { Vale do } \\
\text { Taquari }^{1}\end{array}$ & Estado & $\begin{array}{c}\text { Vale do } \\
\text { Taquari }^{1}\end{array}$ & Estado & $\begin{array}{c}\text { Vale do } \\
\text { Taquari }^{1}\end{array}$ & Estado \\
\hline 1970 & 51,4 & 50,2 & 42,3 & 43,9 & 6,3 & 5,9 \\
1980 & 42,9 & 43,9 & 48,7 & 48,8 & 8,4 & 7,3 \\
1991 & 36,6 & 38,9 & 52,8 & 52,2 & 10,6 & 8,9 \\
2000 & 33,0 & 35,5 & 54,7 & 54,0 & 12,2 & 10,5 \\
2010 & 26,5 & 29,0 & 58,1 & 57,3 & 15,4 & 13,6 \\
\hline
\end{tabular}

Fonte: IBGE (1920 a 2010)

(1) Com base nos dados da população dos municípios existentes na época segundo a atual conformação geográfica;

(2) Foi incluída a população com idade ignorada.

Em 1970, mais da metade da população do VT e do RS estava concentrada na faixa etária entre 0 e 20 anos (51,4\% e 50,2\%, respectivamente). Já em 2010, o maior percentual estava entre a população de 21 a $59 \operatorname{anos}(58,1 \%$ no VT e 57,3\% no RS). Ou seja, apesar de ambos estarem num processo de envelhecimento, a população da região apresenta um envelhecimento mais acelerado do que a média do Estado, dado que em 2010, apenas 26,5\% da população possuía até 20 anos na região, enquanto que no estado esse valor era de $29 \%$. Por outro lado, na região a população com 60 anos ou mais representava 15,4\% do total, e no estado $13,6 \%$.

E na análise municipal, constata-se que em alguns municípios do VT, como em Travesseiro, a participação da população abaixo de 20 anos é reduzida, visto que em 2010 representava $21,69 \%$, enquanto a média da região era de $26,5 \%$. Quanto a população com mais de 60 anos, a média regional era de 15,4\%, no entanto, em alguns municípios essa participação já era superior, como é o caso de Anta Gorda, Dois Lajeados e Forquetinha, onde esse percentual representa $22,04 \%$ ou aquém, como em Lajeado que apresentava o menor percentual, $11,23 \%$. 


\section{TRANSFORMAÇÕES SOCIOESPACIAIS DO VALE DO TAQUARI}

As transformações socioespaciais no VT, objeto de análise deste trabalho, partem do estudo das mudanças constatadas na dinâmica intrarregional da população. Milton Santos sugere que para a análise da espacialidade dos fenômenos considere-se o espaço como totalidade: um conjunto de relações realizadas através de funções, formas e estruturas que se apresentam no processo histórico tanto do passado como do presente. Na contemporaneidade, o fundamento da existência das regiões está baseado em racionalidades de origens distantes, muitos fenômenos que se manifestam na escala local podem ser determinados por outras escalas. Neste sentido, a totalidade do mundo nos remete a análise do espaço geográfico nas suas dimensões local, regional, nacional e global enquanto um indissociável de sistema de objetos (instrumentos de trabalho, cidades, estradas, etc) e sistema de ações (práticas sociais), resultante da acumulação desigual de tempos (SANTOS, 2007), ou seja, cada vez menos os lugares se explicam por si mesmos.

Quando se analisa a literatura sobre a espacialidade das dinâmicas populacionais, verifica-se que em diversas regiões do Brasil e em outros países, parcelas significativas da população passaram a se concentrar em grandes cidades, com mais de 500 mil habitantes. Segundo a ONU (2012), metade da população urbana reside em cidades com mais de 500.000 habitantes. Essa tendência é justificada pela correlação que existe entre o processo de industrialização ocorrido nessas regiões e a urbanização, ou seja, "as indústrias líderes, a partir de sua decisão locacional, representavam uma das principais variáveis na conformação espacial do sistema de cidades" (ANDRADE e SERRA, 1998, p. 3). Por outro lado, cidades intermediárias têm atraído populações de outras regiões em decorrência dos avanços no acesso a água, saneamento, e outros serviços, e assim contribuído para o equilíbrio das cidades nos países (ONU, 2012).

Em busca dessas amenidades, mas que apresentasse um mínimo de especialização, as cidades médias passam a demandar mais atenção entre os anos 80 e 90 . Neste período houve "um encolhimento do ritmo do processo de concentração populacional nas grandes cidades" (SOARES e MELO, 2010, p. 230). Para as autoras, a relativa desconcentração industrial, a interiorização da atividade agrícola, a queda da fecundidade e sucessivas crises foram os principais fatores responsáveis por este fenômeno no Brasil. Os elementos técnicos, científicos, informacionais, e as políticas de investimento em rodovias e em planos diretores 
contribuíram para que as cidades médias não precisassem mais ter intermediação da metrópole.

Na região do VT não existem grandes cidades, apenas quatro podem ser classificadas como cidades médias e as demais são cidades pequenas, contudo algumas cumprem um papel importante para explicar a espacialidade dos movimentos populacionais. Conforme dados do IBGE (2010), das 36 apenas quatro cidades da região concentravam mais de 58,8\% da população, a saber: Lajeado (71.180), Estrela (25.913), Teutônia (23.322) e Taquari (21.875); enquanto que as demais apresentavam menos de 20.000 habitantes, cada uma.

Neste sentido, as análises seguem uma tendência do papel exercido pelas cidades numa região. Não existe consenso que caracterize a cidade média. Esta varia de acordo com as características da região. Quando a abordagem considera simplesmente a questão numérica se trata de cidade de porte médio, porém a cidade média vai além. Ou seja, a cidade de porte médio está diretamente relacionada com a quantidade de habitantes. A cidade média considera o número de habitantes, mas contextualizando com a realidade regional, e, "os papeis de intermediação entre as cidades pequenas e as cidades grandes e metropolitanas, no âmbito de uma mesma rede urbana" (SPOSITO, 2010, p. 52). Com algumas variantes, as cidades que possuem até 20 mil habitantes são consideradas como pequenas, acima deste montante estão as cidades médias e as que possuem mais de 500 mil habitantes são classificadas como grandes (MAIA, 2010).

Estudos realizados por Soares e Melo (2010) indicaram crescimento das cidades médias, em especial no Centro-Sul do Brasil. Abertura de novas oportunidades de trabalho e negócios, o crescimento econômico e a expansão de fronteiras foram fatores que alteraram as características de crescimento e distribuição da população brasileira.

Santos (1993) analisa o processo de urbanização brasileira a partir do movimento do meio técnico-científico, a luz da modernização do campo com seus novos equipamentos como: máquinas, crédito, especialistas, insumos materiais e etc. Neste cenário inicia um processo de transição da cidade dos notáveis para à cidade econômica, mudando assim, o seu conteúdo. $\mathrm{O}$ autor infere que:

Antes, eram as cidades dos notáveis, hoje se transformam em cidades econômicas. A cidade dos notáveis, onde as personalidades notáveis eram o padre, o tabelião, a professora primária, o juiz, o promotor, o telegrafista, cede lugar à cidade econômica, onde são imprescindíveis o agrônomo (o que antes vivia nas capitais), o veterinário, o bancário, o piloto agrícola, o 
especialista em adubos, o responsável pelos comércios especializados (SANTOS, 1993, p. 51).

Na medida em que as técnicas, e mais adiante os sistemas de informática, vão sendo implantados nos territórios, os espaços vão se diferenciando pelo seu conteúdo.

As cidades, ou espaços, que mais concentram a infraestrutura com esses elementos acabam por serem áreas mais aptas a atrair atividades com maior conteúdo em capital, tecnologia e organização (SANTOS, 2007) e por consequência, tornam-se áreas de atração populacional. Por oposição, os espaços onde tais características estão ausentes seriam os espaços de expulsão.

As cidades médias são consideradas fornecedoras de serviços e produtos necessários à população rural e as cidades pequenas. Elas desempenham um papel significativo frente às mudanças na distribuição espacial do Brasil, cada vez mais urbano. Face ao crescimento das metrópoles elas assumem o papel de comando dos aspectos técnicos da produção regional.

Segundo Sposito (2009, p.19) as cidades médias apresentam

[...] o papel de intermediação entre as pequenas e as grandes, então são cidades que comandam uma região, que polarizam uma região, que crescem em detrimento da sua própria região ou crescem em função da sua própria região, as duas coisas acontecem. Cidades médias que ampliam seus papéis, porque diminuem os papéis das cidades pequenas a partir de uma série de mecanismos econômicos, ou cidades que, em função do tipo de atividade que têm, das lideranças que ali se encontram, são capazes de crescer e propor um projeto ou desempenhar um papel político, econômico e social de crescimento para toda uma região.

A difusão das informações e do conhecimento, muitas vezes polarizados nestas cidades, se difunde a partir destes centros via universidades, cursos técnicos, polos tecnológicos, dentre outros. A oferta destes serviços contribui para a modificação da estrutura da própria cidade média a qual passa a contar com uma estrutura econômica mais complexa para suprir a necessidade da demanda regional. Neste sentido, a concentração dos serviços e do PIB nestas cidades são fatores de atração da população, especialmente os mais jovens, que objetivam ingressar no mercado de trabalho.

Na região em estudo, destaca-se as cidades de Lajeado, Estrela e Teutônia, que são as cidades mais populosas da região e geravam 51,1\% do PIB regional em 2010 (FEE, 2010). Considerando apenas Lajeado em relação a região, o PIB gerado representou 29,5\%. Mesmo 
que Lajeado exerça um importante papel, parece relevante também considerar a cidade de Estrela, pois esta é conturbada com Lajeado. Dessa forma Lajeado e Estrela participavam com 41,4\% da geração do PIB regional. Além disso, vale destacar que essas cidades estão situadas na parte central da região.

As cidades pequenas e as grandes metrópoles fazem a intermediação entre o meio rural. De acordo com o estudo das regiões de influência das cidades (IBGE, 2008) a cidade de Lajeado foi classificada como Centro Sub Regional A na hierarquia urbana, tendo como Região de Influência, a Metrópole de Porto Alegre - RS. Como Centro de Zona A estão: Encantado e Estrela. Centro de Zona B: Arroio do Meio, Arvorezinha, Muçum e Teutônia. Como centro local aparecem todas as demais. O estudo levou em consideração as cidades como "centros de gestão", as cidades como nós principais da rede e a região de influência destes centros considerando as redes de interação que conectam as cidades.

Estudos também apontam para uma tendência de aumento dos vínculos com a região metropolitana de Porto Alegre, ou seja, a concentração populacional no VT tem aumentado nas cidades que mais se aproximam da região metropolitana de Porto Alegre.

Além disso, segundo Cargnin e Oliveira (2003), apesar de apresentar ocupação urbana descontínua, a região do VT possui características de complementaridade funcional com tendência à contiguidade com o eixo Porto Alegre - Caxias, referenciadas como um grande conglomerado urbano e industrial. Nas últimas décadas, alguns municípios do VT reforçaram seus vínculos com a região metropolitana, podendo se constituir em um eixo de desenvolvimento de porte semelhante ao já existente entre Porto Alegre e Caxias do Sul.

A confluência da rede modal também se constitui num ponto favorável a esta situação, fato que pode ser pode ser visualizado na Figura 04. A região possui importante sistema de transporte multimodal o que favorece o acesso a mercados regionais, estaduais, nacionais e externos: o eixo rodo-hidro-ferroviário formado pelo Rio Taquari, a BR 386 (Rodovia da Produção); os traçados ferroviários, com rotas interligando o Norte e Centro do Estado e a região Sudeste do país; RS 453; e RS 130. 


\section{Figura 4 - Redes Modais no RS}

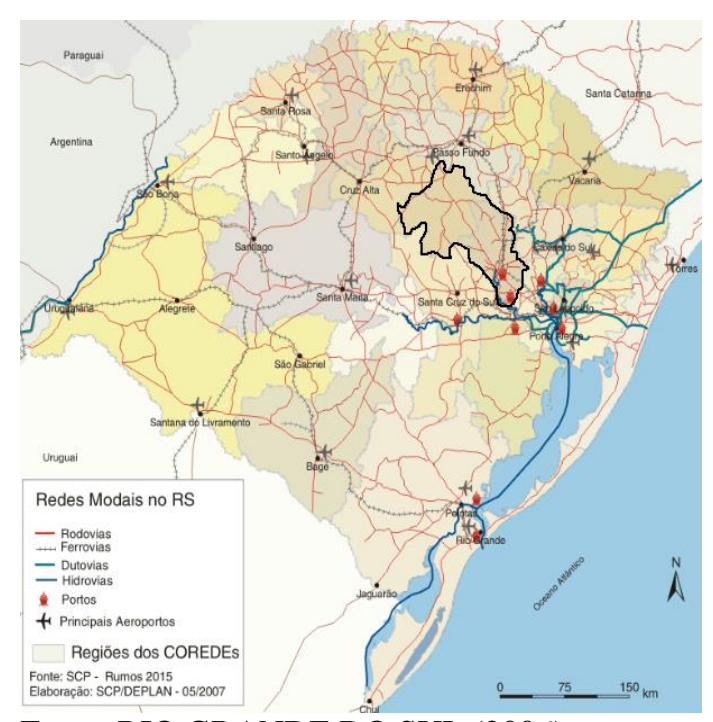

Fonte: RIO GRANDE DO SUL (2006)

Conforme verificado, a região do VT possui uma boa conexão via redes modais com as demais regiões do RS, em especial com a região metropolitana, o que também tem contribuído no processo de descentralização concentrada dessa região, com a criação de novas concentrações industriais (RIO GRANDE DO SUL, 2006).

\section{CONSIDERAÇÕES FINAIS}

A região do VT ao longo das décadas de 1970 a 2010 apresentou um processo de urbanização crescente e uma modificação na dinâmica da economia regional, com mudanças na predominância das atividades econômicas e na geração da riqueza. Também evoluiu para uma forte concentração da produção do PIB e da população em algumas cidades, destacandose Lajeado.

A maior parte população do VT migrou da zona rural para a zona urbana e dos municípios menores para os municípios maiores, demonstrando ao longo deste período um quadro de inversão da participação do meio rural e do meio urbano.

A reconfiguração espacial acompanhou as transformações oriundas do processo de modernização, do novo conjunto de técnicas e tecnologias. Neste contexto houve uma redistribuição espacial de sua população. 
Por outro lado, a composição da estrutura etária da população se modificou, a população da região seguiu a tendência de envelhecimento, porém num ritmo superior ao verificado no RS.

O processo de urbanização da região ocorreu de forma desigual entre os municípios, em alguns, a população passou a residir essencialmente nas zonas urbanas e com o predomínio de atividades industriais e no setor de serviços como Lajeado e outros no seu entorno. No caso de Lajeado, a taxa de urbanização, em 2010, chegou a 99,62\% e a densidade demográfica de $792,95 \mathrm{hab} / \mathrm{km}^{2}$. Constatou-se que cinco municípios que lideram a geração do PIB da região são os que apresentam maior densidade demográfica. Destes, quatro concentravam mais de $58,8 \%$ da população da região. Em alguns mais distantes do polo regional, a maioria da população permaneceu residindo nas zonas rurais e vinculadas as atividades do setor primário. O número de municípios é significativo, são 21 dos 36 municípios, porém a população é bem reduzida em relação aos demais. São $26,2 \%$ do total da população da região que reside em áreas rurais enquanto que 73,8\% em áreas urbanas.

A dinâmica econômica e populacional estabelecida na região levou a uma nova configuração espacial, aliada as ligações proporcionadas pela sua rede modal, estabeleceram vínculos importantes entre o VT e eixo de desenvolvimento do RS, quais sejam: a região metropolitana de Porto de Alegre e de Caxias do Sul.

\section{REFERENCIAS}

ANDRADE, Thompson Almeida; SERRA, Rodrigo Valente. O recente desempenho das cidades médias no crescimento populacional urbano brasileiro. Texto para Discussão no 554. Rio de Janeiro: IPEA, março de 1998.

CAMARANO, A. A.; BELTRÃO, K.I.. Distribuição espacial da populacional brasileira: mudanças na segunda metade deste século. Texto para discussão no. 766. Rio de Janeiro: IPEA, 2000.

CARGNIN, A.P.; OLIVEIRA, S.B. Temas para o desenvolvimento territorial no estado do Rio Grande do Sul. Texto para discussão. Secretaria da Coordenação e Planejamento Seplag. RS, 2003.

CORRÊA, Roberto Lobato. Construindo o conceito de cidade média. In: SPOSITO, Maria Encarnação B. (Org.). Cidades médias: espaços em transição. São Paulo: Expressão Popular, 2007.

FEE - Fundação de Economia e Estatística. Feedados. Porto Alegre: FEE, 2010.

IBGE - Instituto Brasileiro de Geografia e Estatística. Censo Demográfico. Rio de Janeiro: IBGE, 1970. 
Censo Demográfico. Rio de Janeiro: IBGE, 2000.

Censo Demográfico. Rio de Janeiro: IBGE, 2010.

Regiões de influências das cidades 2007 (Regic). Instituto Brasileiro de Geografia e Estatística, Rio de Janeiro, Brasil, 2008.

MAIA, Doralice Sátiro. Cidades médias e pequenas do nordeste. Conferência de abertura In: MERLIN, D.; HENRIQUE, W. (Org.). Cidades médias e pequenas: teorias, conceitos e estudos de caso. Salvador: SEI, 2010, v. 1, p. 13-37.

ONU-Habitat. Estado de lãs ciudades de América Latina y el Caribe 2012: rumbo a una nueva transicion urbana. ONU-Habitat, Agosto del 2012. Disponível em: http://www.unhabitat.org. Acessado em 27 de agosto de 2012.

RIO GRANDE DO SUL. SCP. Rumos 2015. SCP/DEPLAN-DCAPET. Porto Alegre. SCP. 2006

SANTOS, Milton. A Natureza do espaço: Técnica e tempo. Razão e emoção. São Paulo: Hucitec, 2007.

SANTOS, Milton e SILVEIRA, María Laura. Brasil: Território e Sociedade no Início do Século XXI. Rio de Janeiro: Record, 2008.

. A Urbanização brasileira. São Paulo: Hucitec, 1993.

SOARES, Beatriz Ribeiro; MELO, Nágela Aparecida de. Cidades Médias e pequenas: reflexões sobre os desafios no estudo dessas realidades socioespaciais. In: LOPES, Merlin, Diva Maria; HENRIQUE, Wendel. (Org.). Cidades médias e pequenas: teorias, conceitos e estudos de caso. Salvador: SEI, 2010, v. 1, p. 229-251.

SPOSITO, Maria Encarnação Beltrão. Para pensar as pequenas e médias cidades brasileiras. Belém: FASE/ICSA/UFPA, 2009.

Novas redes urbanas: cidades médias e pequenas no processo de globalização. Geografia, Rio Claro, v.35,nº 1,p. 51-62, jan./abr. 2010.

Recebido em 31 de maio de 2017.

Aceito em 28 de novembro de 2017. 